\title{
Anti-IGF-1R Monoclonal Antibody AVE1642
}

National Cancer Institute

\section{Source}

National Cancer Institute. Anti-IGF-1R Monoclonal Antibody AVE1642. NCI Thesaurus.

Code C79798.

A humanized monoclonal antibody directed against the human insulin-like growth factor1 receptor (IGF-1R/CD221) with potential antineoplastic activity. Anti-IGF-1R monoclonal antibody AVE1642 specifically binds to and blocks membrane-bound IGF-1R, preventing the binding of the natural lig and IGF-1 and the subsequent activation of PI3K/AKT signal transduction, which may result in the induction of apoptosis and a decrease in cellular proliferation. Activation of IGF-1R, a receptor tyrosine kinase of the insulin receptor superfamily overexpressed by various cancer cell types, stimulates cell proliferation, promotes angiogenesis, enables oncogenic transformation, and suppresses apoptosis. 